\title{
Comparison and Selection Criterion of Missing Imputation Methods and Quality Assessment of Monthly Rainfall in The Central Refit Valley Lakes Basin of Ethiopia
}

Sisay Kebede Balcha ( $\square$ kenasisay@gmail.com )

Addis Ababa University https://orcid.org/0000-0001-8424-2928

Taye Alemayehu Hulluka

Addis Ababa University

Adane Abebe Awass

Arba Minch University

Amare Bantider

Addis Ababa University

\section{Research Article}

Keywords: Missing data, Missing Imputation, Compromise Programming, Homogeneity test, Trend test, Central Rift Valley Lakes subbasin

Posted Date: November 2nd, 2021

DOI: https://doi.org/10.21203/rs.3.rs-961075/v1

License: (c) (i) This work is licensed under a Creative Commons Attribution 4.0 International License.

Read Full License 


\title{
Comparison and Selection Criterion of Missing Imputation Methods and Quality Assessment of Monthly Rainfall in the Central Refit Valley Lakes Basin of Ethiopia
}

\author{
Sisay Kebede Balcha ${ }^{a, *}$, Taye Alemayehu Hulluka ${ }^{a}$, Adane Abebe Awass ${ }^{b}$, Amare Bantider ${ }^{\mathrm{c}}$ \\ ${ }^{a}$ Ethiopian Institute of Water Resources, Addis Ababa University, Addis Ababa, Ethiopia \\ ${ }^{\mathrm{b}}$ Institute of Technology, Arba Minch University, Arba Minch, Ethiopia \\ ${ }^{\mathrm{c}}$ Water and Land Resources Center, Addis Ababa University, Addis Ababa, Ethiopia
}

\begin{abstract}
Missing data is a common problem in all scientific research and the availability of gap-free data is rare in most developing countries. Statistical and empirical methods are the most often used for approximation of missing data. The performance of eight missing estimation methods was evaluated using bias, RMSE, and NSE. The Multicriteria decision method of compromise programing approach was used to identify the best imputation method. Four homogeneity test methods were used to evaluate the homogeneity of the time series data. The Mann-Kendall trend test and Son's slope were used to locate the change and calculate the magnitude of the trend. Multiple Linear Regression and Multiple Imputation by chained equations were well performed over most stations. Alternatively, the modified version of IDWM based on spatial distance and elevation difference (IDWM $\mathrm{E}_{\mathrm{D} 3}$ ) was ranked as third at many stations. The inclusion of elevation differences between stations has improved the capability of the inverse distance weight method. However, the performance of all the missing estimation methods decreased as the percentage of missing increased. Radius influences have no significant impact on the performance of missing imputation methods. Only Butajera station exhibited nonhomogeneous. Dagaga, Iteya, Bui, and Butajera stations all exhibited decreasing trends. Kulumsa and Ejerese-lele stations presented an increasing trend in monthly rainfall. However, the rest station has shown no significant increasing or decreasing trends in monthly rainfall.
\end{abstract}

Key Words Missing data; Missing Imputation; Compromise Programming; Homogeneity test; Trend test; Central Rift Valley Lakes subbasin

${ }^{*}$ Corresponding Author: Sisay Kebede Balcha

E-mail address: kenasisay@gmail.com

ORCID: 0000-0001-8424-2928

\section{Introduction}

Missing data is a common problem in all scientific research, project planning, and development of water resource infrastructures. It (i) reduces the power and precision of statistical analysis results (Piazza, 2011; Houari et al., 2014; Schmitt et al., 2015; Gao et al., 2018); (ii) leads to a biased estimate and draws the wrong conclusion about the relationship between two or more variables (Pigott, 2001; Gao et al., 2018; Ekeu-wei et al., 2018; Gao et al., 2018; Teegavarapu et al., 2019). It is very common in hydrology and other related fields to estimate the missed values of a target station from the values of neighboring stations. There are various methods available to approximately calculate the missing value of the target station and they are grouped as empirical, statistical, and function fitting methods (Xia et al., 1999; Sattari et al., 2016). Unusually, deleting or substituting missing values by the arithmetic mean or median are used as alternative methods (Peugh and Enders, 2004). Modern approaches, including spatial interpolation techniques such as Inverse Distance Weighting Average (IDWA), Normal Ratio (NR), simple Arithmetic Average (AA), Kriging, and co-Kriging, are the most widely used techniques in different geographic locations (Hartkamp et al., 1999; Ferrari and Ozak, 2014; El Kasri et al., 2018; Barrios et al., 2018). The statistical methods, including correlation coefficient weighting (CCW) and multiple linear regression (MLR), are used alternatively to compute the missing values of the target station (Xia et al., 1999; Barrios et al., 2018). Recently, the advance of big data analysis and the computing power of the computer have created an opportunity for the development of Multiple Imputation by Chained Equation (MICE) (Peugh and Enders, 2004; Schmitt et al., 2015; Gao et al., 2018).

Choosing any of the methods among the alternatives depends on the characteristics of the observed variables (Gao et al., 2018), geographic location and spatial distance between the stations (Barrios et al., 2018), percentage of missing data (Radi et al., 2015) and characteristics of the missing mechanism (Rubin, 1976; El Kasri et al., (2018). It is very common to use any of the imputation methods based on an individual's preferences, knowledge, or experience (Kashani and Dinpashoh, 2012). But, random use of any missing estimation method without evaluating its 
performance will increase the error value and reduce the ability of the statistical results (Ismail and Ibrahim, 2017; Barrios et al., 2018; El Kasri et al., 2018).

Recently, research has started to evaluate the ability of missing imputation techniques using statistical metrices. As an example, Barrios et al., (2018) evaluated the capability of the five missing estimation methods and the impact of radius of influence on the complex topography of central South Chile and found the ANN, MLR, and IDW had produced the lowest errors and the best method for filling the gap of missed monthly rainfall. El Kasri et al., (2018) have evaluated the performance of five imputation methods in the southern Atlas of Morocco, and have recommended the Theisen polygon, normal ratio, inverse distance weighted, and multiple imputation, methods as the best methods for filling the gap of missed rainfall. Similarly, Ismail and Ibrahim, (2017) have recommended the inverse distance weighted and correlation coefficient methods to fill the data gap. The Normal Ratio (NR) and Multiple Imputation (MI) methods are considered as the most appropriate methods by Radi et al., (2015) at 5\%,10\%, and 20\% to represent various cases of missing data percentages.

All the above-mentioned studies have evaluated the ability of different missing imputation methods, and there are no significant studies reported to consider the problem from a multi-objective perspective and clear approach or criteria to select the best method from a wide range of alternatives for missing data management. This is more of a series in an area of complex topography, sparsely and unevenly located measuring stations, and specific climate conditions like the Central Rift Valley Lakes subbasin. For example, stations found at high altitude have received the highest amounts of rainfall compared to stations at lower altitude in the study region. Even so, stations located at similar altitude but in opposite directions, such as Leeward or Windward, have exhibited different agroecology and rainfall amounts. With this understanding, the proposed objectives of the study are: (i) identify performance metrics and evaluate the ability of eight missing imputation methods; (ii) application of a compromise programing method to rank and select the best imputation method; and (iii) assess the homogeneity and trend of the monthly precipitation dataset for each station.

\section{Materials and Methods}

2.4. Description of study area

The Great Rift of the Earth runs from Jordan southward through East Africa to Mozambique (Meshesha et al., 2012). The Ethiopian rift extends from the Kenya border up to the Red Sea and is divided into three subsystems: Chew Bahir (Lake Stephanie), the Central Rift Valley Lakes subbasin, "hereafter referred to as CRV Lakes subbasin" and the Afar triangle. The Katar and Meki watersheds are located in the CRV Lakes subbasin of Ethiopia's Rift Valley Lakes Basin. Geographically, the Katar watershed extend between 38.880 to 39.410 E longitude, 7.36 to $8.180 \mathrm{~N}$ latitude eastward of Lake Ziway. The Meki watershed is extended between 38.220 to $39.000 \mathrm{E}$ longitude and 7.830 to $8.460 \mathrm{~N}$ latitude westward of Lake Ziway. The altitudes are extended between 1630 to 4188 and 1624 to 3614 meters a.m.s.l. for the Katar and Meki watersheds, respectively (Figure 1). 


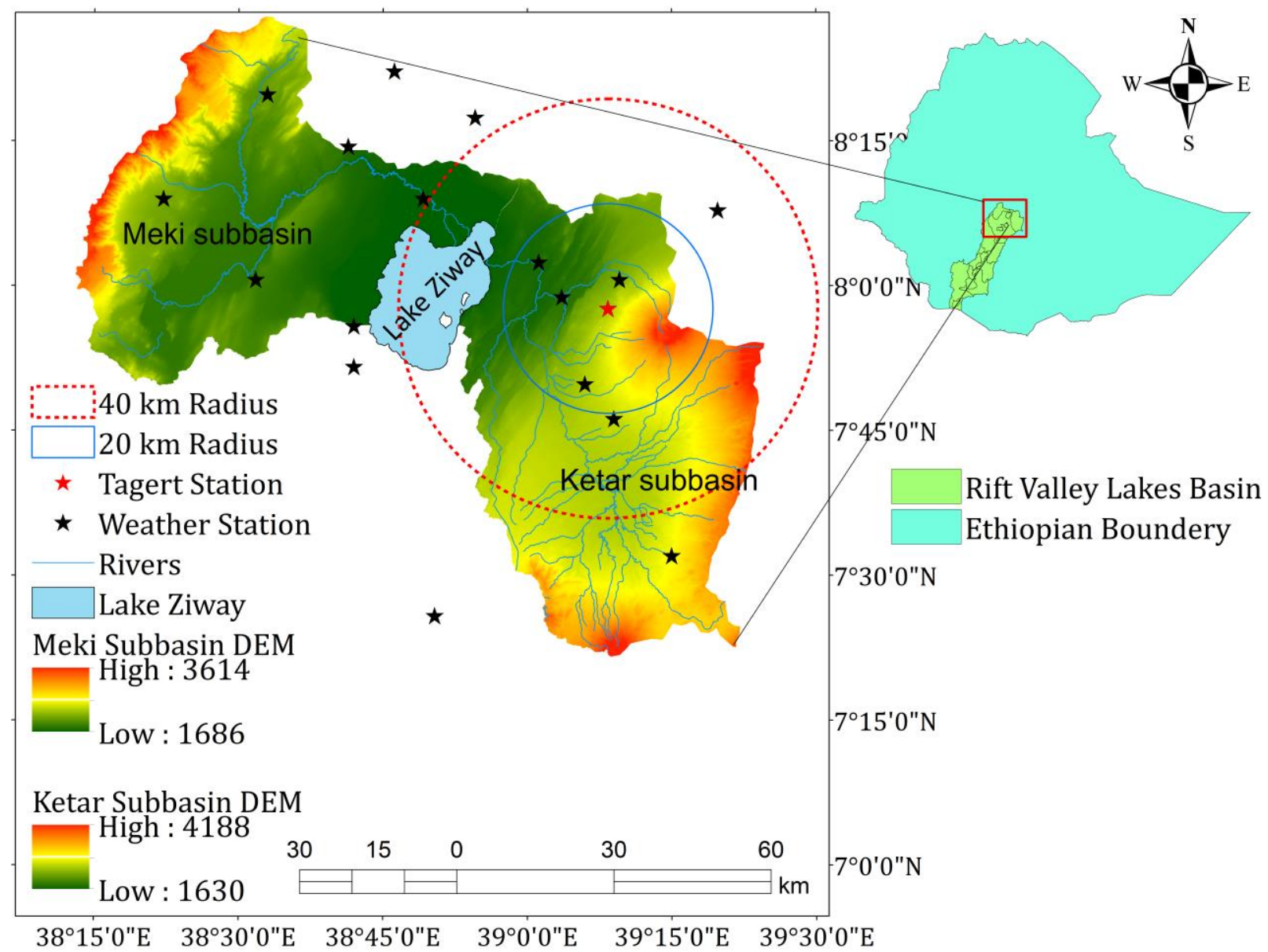

Fig. 1 Location of the study area, target station (red star) and neighboring stations (black star). The elevation data extracted from a $30 \mathrm{~m}$ resolution of Shuttle Radar Topographic Mission

\subsection{Data accusation}

\subsubsection{Observed data}

Monthly observed rainfall data for 22 meteorological stations was collected from National Meteorology Agency of Ethiopia (ENMA) for the time intervals of 1 January 1997 to 31 December 2017. Exploratory data analysis includes prescreening of negative values of precipitation, multiple dots between values, and computing the missing percentage and the outlier for each station. Additionally, the spatial distances between stations were calculated to determine the maximum radius of influence. Stations that were more than 40 kilometers away from any other station and had more than $25 \%$ missing values been excluded from the analysis. Sixteen meteorological stations were selected in this study for further analysis (Table 1).

Table 1 Geographic location of selected stations, average rainfall, and percentage of missed precipitation (19832005).

\begin{tabular}{|l|l|l|l|l|l|l|l|l|}
\hline Basins & № & Name & Latitude & Longitude & Ele. $(\mathrm{m})$ & $\mu \mathrm{RF}$ & $\sigma \mathrm{RF}$ & \%MD \\
\hline \multirow{5}{*}{ Katar watershed } & 1 & Arata & $7.97^{0}$ & $39.05^{0}$ & 1765.00 & 766.46 & 98.37 & 10.14 \\
\cline { 2 - 9 } & 2 & Asella & $7.95^{0}$ & $39.13^{0}$ & 2413.00 & 1053.98 & 149.64 & 7.61 \\
\cline { 2 - 9 } & 3 & Katar-genet & $7.83^{0}$ & $39.10^{0}$ & 2400.00 & 801.38 & 202.77 & 22.1 \\
\cline { 2 - 9 } & 4 & Kulumsa & $8.00^{0}$ & $39.15^{0}$ & 2211.00 & 812.18 & 85.40 & 0.36 \\
\cline { 2 - 9 } & 5 & Ogolcho & $8.05^{0}$ & $39.00^{0}$ & 1682.00 & 710.68 & 150.05 & 8.7 \\
\cline { 2 - 9 } & 6 & Sagure & $7.75^{0}$ & $39.15^{0}$ & 2568.00 & 772.68 & 129.75 & 5.8 \\
\cline { 2 - 9 } & 7 & Dagaga & $7.43^{0}$ & $38.84^{0}$ & 2067.00 & 1049.89 & 135.74 & \\
\cline { 2 - 9 } & 8 & Iteya & $8.13^{0}$ & $39.33_{0}$ & 2129.00 & 1044.65 & 321.83 & 19.93 \\
\hline & 9 & Alem-tena & $8.29^{0}$ & $38.91^{0}$ & 1656.00 & 840.14 & 106.74 & \\
\hline
\end{tabular}




\begin{tabular}{|l|l|l|l|l|l|l|l|l|}
\hline \multirow{4}{*}{ Meki watershed } & 10 & Butajera & $8.15^{0}$ & $38.37^{0}$ & 2000.00 & 1010.76 & 423.32 & 12.68 \\
\cline { 2 - 9 } & 11 & Bui & $8.33^{0}$ & $38.55^{0}$ & 2054.00 & 973.24 & 188.82 & 25.0 \\
\cline { 2 - 8 } & 12 & Adami-tulu & $7.86^{0}$ & $38.70^{0}$ & 1653.00 & 854.70 & 273.84 & 24.64 \\
\cline { 2 - 9 } & 13 & Ziway & $7.93^{0}$ & $38.70^{0}$ & 1640.00 & 743.92 & 136.43 & 3.62 \\
\cline { 2 - 9 } & 14 & Ejerse-lele & $8.24^{0}$ & $38.69^{0}$ & 1797.00 & 862.13 & 171.66 & 4.35 \\
\cline { 2 - 9 } & 15 & Koshe & $8.01^{0}$ & $38.53^{0}$ & 1878.00 & 760.19 & 209.16 & 4.71 \\
\cline { 2 - 8 } & 16 & Meki & $8.15^{0}$ & $38.82^{0}$ & 1662.00 & 742.82 & 98.54 & 14.13 \\
\hline
\end{tabular}

Note: $\mu \mathrm{RF}$ is mean annual rainfall; $\sigma \mathrm{RF}$ is the standard deviation of rainfall, $\% \mathrm{MD}$ is the percent of missed data, Ele is the elevation in meters, lat. is latitude, Lon is longitude.

\subsubsection{Reanalysis data}

In Ethiopia, most stations are unevenly located on the main roads of cities and do not provide timely or sufficient data free of missing value. This is causing inhomogeneity, abrupt change, and trends in climate datasets. The reanalysis data has been extensively used as an alternative source of information for the study of climate variability (Dile and Srinivasan, 2013; Fuka et al., 2013; Funk et al., 2015; Alhamshry et al., 2020) and to evaluate the ability of regional climate model (RCMs) output (Bichet et al., 2020). In this study, the Climate Hazards Group Infrared Precipitation with Station (CHIRPS) was downloaded from http://climateserv.servirglobal.net/site for the time span of 1983-2005 to assess the ability of missing imputation methods.

\subsection{Approaches of the Evaluation}

Four steps are followed to assess the performance of missing imputation methods. Monthly CHIRPS datasets of each grid point were extracted using a python script and interpolated into each meteorological station using four grid points around each observed station using IDWM (Table 1). Then, they deliberately and randomly assigned NA (Not Available) complete datasets of CHIRPS using R-program to represent different levels of missing percentage of 5\%, $10 \%, 15 \%, 20 \%$, and $25 \%$ of Table 1 using R software. Second, stations within a 20 -and 40 -kilometer radius of influence from the target station were considered as neighboring stations and recalculated the missed values of target stations using eight imputation methods. Third, the ability of the imputation method was evaluated using RMSE, PBIAS, and NSE. Fourth, multicriteria decision methods of compromise programming were applied to identify the best imputation method for each station, and finally, the quality of the data was studied for homogeneity and trend using the selected methods.

\subsection{Methods of missing imputation Techniques}

\subsubsection{Spatial Imputation Method}

A deterministic spatial interpolation technique such as the inverse distance weighting method is modified based on elevation difference, correlation coefficient (CC) and a combination of correlation coefficient or Euclidian distance as weighting factors to estimate missing values for the target station (Vieux, 2004; Barrios et al., 2018). The details of each method are given below.

\section{a. Invers Distance Weighted Average (IDWA)}

The Inverse distance weighting method is commonly used for approximately calculating missing data (Teegavarapu and Chandramouli, 2005). The missing value of the target station is determined from the observed values of neighboring stations using Eq. 1 (Vieux, 2004; Barrios et al., 2018).

$$
P_{m i}=\frac{\sum_{i=1}^{n} \boldsymbol{d}_{\boldsymbol{m i}}^{-\boldsymbol{k}} * \boldsymbol{q}_{\boldsymbol{j}(\boldsymbol{i})}}{\sum_{i=1}^{n} \boldsymbol{d}_{\boldsymbol{m i}}^{-\boldsymbol{k}}}
$$

Where $P_{m i}$ is the calculated missing value of the target station, $n$ is the number of neighboring stations, $d_{m i}$ is the Euclidian distance between the target and neighboring station $\mathrm{i}$, and $\mathrm{q}_{\mathrm{j}(\mathrm{i})}$ is the observed value at station $\mathrm{i}$. $\mathrm{k}$ is a coefficient and its value varies between 1 and 6 , but the most commonly suggested value is 2 (Teegavarapu and Chandramouli, 2005). The negative sign of $\mathrm{k}$ implies that stations closer to the target stations are more important than those farther away (Vieux, 2004). The Euclidian distance between the target and neighboring stations is calculated using Eq. 2 (Barrios et al., 2018).

$$
d_{m(i)}=\frac{\sqrt{\left(X_{i}-X_{m}\right)^{2}+\left(Y_{i}-Y_{m}\right)^{2}}}{1000}
$$

Where $X_{i}$ and $Y_{i}$ are the projected coordinates of the neighboring stations, and $X_{m}$ and $Y_{m}$ are the projected coordinates of the target station. 


\section{b. Modified Inverse Distance Weighting $\left(M I D W_{E \& D}\right)$ based on Elevation}

Elevation is one of the topographic factors that significantly affects the spatiotemporal distribution of precipitation and other climate variables (Golkhatmi et al., 2012). As long as the elevation difference has an effect, the conventional inverse distance weighted method is modified by the inclusion of the elevation difference between the target and neighboring stations and missing values of the target station calculated using Eq. 3 (Barrios et al., 2018).

$$
P_{m i}=\frac{\sum_{i=1}^{n} \boldsymbol{h}_{\boldsymbol{m} i}^{-\boldsymbol{a}} * \boldsymbol{d}_{\boldsymbol{m}}^{-\boldsymbol{k}} * \boldsymbol{q}_{\boldsymbol{j}(i)}}{\sum_{i=1}^{n} \boldsymbol{h}_{\boldsymbol{m} i}^{-\boldsymbol{a}} * \boldsymbol{d}_{\boldsymbol{m i}}^{-\boldsymbol{k}}}
$$

Where $\mathrm{h}_{\mathrm{mi}}$ is the elevation difference between the target and the neighboring station, and the exponent "a" is a power parameter and its value ranges from 1 to 3 , with the most commonly used value being 1 (Barrios et al., 2018).

\section{c. Modified Inverse Distance Weighted (MIDWM $\left.M_{D \& C}\right)$ based on Correlation coefficient}

For orographic and complex climate regions, the normal inverse distance weighted method is modified based on spatial distance and correlation coefficient between the target and the neighboring station (Romero et al., 1998). The missed value of the target station is estimated from the neighboring station by Eq. 4.

$$
P_{m i}=\frac{\sum_{i=1}^{n} \boldsymbol{\alpha}_{\boldsymbol{j}(i)} * \boldsymbol{q}_{\boldsymbol{j}(i)}}{\sum_{i=1}^{n} \boldsymbol{\alpha}_{\boldsymbol{j}(i)}}
$$

$\alpha_{\mathrm{j}(\mathrm{i})}$ is the weighting factor between the target station and the neighboring stations. The weighting factor is calculated by using the Euclidian distance and Pearson correlation target and neighboring stations by Eq. 5 .

$$
\alpha_{j(i)}=\frac{R_{j(i)}^{2}}{d_{j(i)}^{2}}
$$

Where, $\mathrm{R}_{\mathrm{j}(\mathrm{i})}{ }^{2}$ is the correlation coefficient between the target station and the neighboring stations.

d. Coefficient of Correlation weighting method (CCWM)

In this version of the inverse distance weighting method, the weighting factors are substituted by the correlation coefficient (Teegavarapu and Chandramouli 2005; Teegavarapu 2009), and the missing value of the target station is given by Eq. 6 .

$$
P_{m i}=\frac{\sum_{i=1}^{n} \boldsymbol{R}_{\boldsymbol{j}(i)} * \boldsymbol{q}_{\boldsymbol{j}(i)}}{\sum_{i=1}^{n} \boldsymbol{R}_{\boldsymbol{j}(i)}}
$$

Where $\mathrm{R}_{\mathrm{j}(\mathrm{i})}$ is the coefficient of correlation, which is the ratio of covariance between the target and neighboring stations to the product of the standard deviation of the datasets. Its values are derived from available historical data.

\subsubsection{Multiple Linear Regression (MLR)}

Multiple linear regressions (MLR) are a statistical method used to estimate the relationship between one dependent and two or more independent variables. It is used to identify the best weighted combination of independent variables to predict the dependent variable (Sattari et al., 2017). Eisched et al., (1995) emphasized the benefits of the multiple linear regression method for interpolating missed data using Eq. 7.

$$
P_{m i}=a_{j(o)}+\sum_{i=1}^{n} a_{j(i)} q_{j(i)}
$$

Where $\mathrm{a}_{\mathrm{j}(\mathrm{i})}$ is the regression coefficient, and $\mathrm{a}_{\mathrm{j}(0)}$ is the intercept.

\subsubsection{Multivariate Imputation by Chained Equation (MICE)}

Multivariate imputation by chained equations is known as sequential regression imputation, which estimates several missing values systematically and generates distinct sets of complete datasets. In this method, the incomplete dataset can be copied several times and the missing values are imputed to each copied dataset differently. The imputed missed values are randomly estimated for each copied dataset and combined into the average value of the dataset (Ibrahim et al., 2005). The R package of Bayesian based MICE functions is available to compute missing values of the target station from the values of the neighboring stations. The default setting was used in the MICE function to generate 
different imputed datasets using the predictive mean matching method (pmm) and five $(\mathrm{m}=5)$ number of imputations. Finally, the imputed values were averaged to represent the missed value of the target station.

\subsection{Accuracy Assessment Methods}

There are several model accuracy assessment metrics described in the literature (Moriasi et al., 2007). Root mean square error (RMSE), Nash-Sutcliff $\left(\mathrm{NS}_{\mathrm{E}}\right)$, and percent of bias (PBIAS) are commonly used to assess the performance and predictive capability of missing estimation methods (Moriasi et al., 2007; Barrios et al., 2018). RMSE can measure the error between the observed and predictive values and give greater weight to any extreme outliers present in the prediction results (Plouffe et al., 2015). The optimal value varies between zeros, which means no residual variation and perfect model simulation, and a greater positive value (Moriasi et al., 2007) and calculated by Eq. 8.

$$
R M S E=\left(\frac{\left(\sum_{i=1}^{n}\left(Y_{o i}-Y_{s i}\right)^{2}\right.}{\left(\sum_{i=1}^{n}\left(Y_{o i}-Y_{m i}\right)^{2}\right.}\right)^{1 / 2}
$$

According to Moriasi et al., (2007) and Barrios et al., (2018), "Nash-Sutcliffe efficiency is a normalized statistic that determines the relative magnitude of the residual variance (noise) compared to the measured data variance (information)". It shows the degree of observed versus simulated aligned on the plot of the 1:1 line (Nash and Sutcliffe, 1970) and calculated by Eq. 9.

$$
N S_{E}=1-\left(\frac{\left(\sum_{i=1}^{n}\left(Y_{o}-Y_{s}\right)^{2}\right.}{\left(\sum_{i=1}^{n}\left(Y_{o}-Y_{m}\right)^{2}\right.}\right)
$$

Where $\mathrm{Y}_{\mathrm{oi}}$ is the $\mathrm{i}^{\text {th }}$ observed value, $\mathrm{Y}_{\mathrm{si}}$ is the $\mathrm{i}^{\text {th }}$ simulated value for $\mathrm{Y}_{\mathrm{m}}$ is the mean of observed data, and $\mathrm{n}$ is the total number of observations. The NSE ranges between $-\infty$ and 1.0 , with $\mathrm{NS}_{\mathrm{E}}=1$ being the ideal value and values between 0 and 1 being the range for acceptable levels of performance, while values $<0.0$ indicate unsatisfactory performance and the observed value is better predictor than the simulated (Moriasi et al., 2007).

Percent of bias (PBIAS) measures the average difference between the simulated and observed counterparts (Moriasi et al., 2007; Barrios et al., 2018) and is calculated by Eq. 10.

$$
P B I A S=100 *\left(\sum_{i=1}^{n}\left(Y_{o i}-Y_{s i}\right) / \sum_{i=1}^{n}\left(Y_{o i}\right)\right)
$$

The optimal values of PBIAS vary between zero for perfect model simulation and a positive or negative value that shows model underestimation or over estimation of bias, respectively (Moriasi et al., 2007).

\subsection{Multicriteria Decision Method (MCDM) of Compromise programing}

There are several decision-making methods for different problems (Sabaei et al., 2015; Mardani et al., 2015; Majmder, 2015; Raju \& Kumar, 2018). The multicriterion decision method of Compromise programing (CP) is used to measure the minimum distance between the ideal value and performance indicators to identify and rank the missed imputation by Eq. 11 (Raju et al., 2016).

$$
L_{p(a)}=\left[\sum_{j=1}^{J} w_{j}^{p}\left(f_{j}^{*}-f_{j(a)}\right)^{p}\right]^{\frac{1}{p}}
$$

Where indicators $j=1,2 \ldots J, L_{p(a)}=L_{p}$ metric for imputation method a for the chosen value of parameter $p$, $f_{j(a)}=$ Normalized value of indicator $\mathrm{j}, \mathrm{w}_{\mathrm{j}}=$ weight of performance indicator $\mathrm{j}$ got from the entropy method, $\mathrm{p}=$ parameter (1 for linear, 2 for Euclidean distance measure) and for this study we adopted the p value of 2. Based on the minimum value of the $L_{p}$ metrics, the imputation methods were ranked accordingly and the best method was proposed for each station. To decide independently of the views of the decision maker, normalizing and weighting of the performance indicators is required. The Entropy method is used to normalize and estimate the weight of various criteria from the given payoff matrix (Pomerol and Romero, 2000; Raju \& Kumar, 2014; Zhu et al., 2020). First, the performance indexes are standardized and the payoff matrix $\left(\mathrm{P}_{\mathrm{ij}}\right)$ is calculated using Eq. 12 (Zhu et al., 2020). 


$$
P_{i j}=\frac{P_{i j}}{\sum P_{i j}}
$$

For a given normalized payoff matrix $\mathrm{p}_{\mathrm{ij}}$, an entropy $\mathrm{E}_{\mathrm{i}}$ is calculated using Eq. 13 for a set of alternative criterion $\mathrm{j}$.

$$
E_{j}=\frac{1}{\ln (N)} \sum_{i=1}^{N} p_{i j} \ln \left(p_{i j}\right) \quad \text { for } j=1, \ldots J
$$

Where $\mathrm{N}$ is the number of imputation techniques and $\mathrm{j}$ is the number of indicators. Degree of diversification of the information provided by the outcomes of criterion $\mathrm{j}$ calculated by Eq. 14 .

$$
D_{j}=1-E_{j} \quad \text { for } j=1, \ldots, J
$$

Then finally, the normalized weights of indicators calculated by Eq. 15 .

$$
w_{j}=\frac{D_{j}}{\sum_{i=1}^{J} D_{j}}
$$

\subsection{Data Quality Check \\ 2.7.1. Homogeneity test}

In order to conduct reliable studies on climate variability, good quality and long-term datasets are required. Actually, many studies have confirmed that climate change analyses are not possible without a clear understanding of the homogeneity of data. There is an assumption that the climate record is considered homogeneous when its variations are caused only by changes in weather and climate (Caloiero et al., 2020; Kocsis et al., 2020; Patakamuri et al., 2020). However, there are non-climatic factors that make the magnitude of climate signals larger than the actual (Caloiero et al., 2020).

The following are the four test techniques that were chosen to assess the time series departure from homogeneity: The Standard Normal Homogeneity Test (SNHT), which is sensitive to detecting the breaks near the beginning and end of the data (Alexandersson, 1986), Buishand's Range Test (BRT) (Buishand, 1982), and the Pettit Test (Pettitt, 1979), are sensitive to locating the breaks in the middle of the series, and the Von Neumann Range Test (VNRT) don't located the location of the break (Von Neumann, 1941). But, if there is a break in the data, the test statistics less than two and if not, the test statistics equal to two. Generally, the first three tests are able to locating the year of break that is likely to occur. The Pettitt test, unlike the SNHT and the Buishand's range test, does not assume that Xi values are regularly distributed. Since the Pettitt test is based on the rankings of the elements of a series rather than on the values themselves, such an assumption is not required. All tests are executed under the null hypothesis that annual values Xi of the testing variable $\mathrm{X}$ are independent and identically distributed. The alternative (Ha) hypothesis for NSHT, BRT, and PTT is a step-wise shift in the mean of the data. However, the alternative hypothesis for VNRT assumes that the time series data is not randomly distributed. All these were conducted using XLSTAT 2020. Then finally, the test results have been summarized by Wijngaard et al., (2003) as: useful (when the test has rejected none or one null hypothesis out of four tests), doubtful (when the test has rejected two null hypotheses out of four tests) and suspect (when the test has rejected three or all null hypotheses out of four tests).

\subsection{2. $\quad$ Trend analysis}

The Mann-Kendall Trend (MK) test is a non-parametric test which is used to determine the presence or absence of mnotonic trends in time series data of a candidate station (Kocsis et al., 2020). The null hypothesis (Ho) of MK is that there is no trend, and the alternative hypothesis $(\mathrm{Ha})$ is that the time series of a candidate station follows a monotonic trend over time. The Mann-Kendall test statistic is calculated by (Eq. 16).

$$
S=\sum_{i=1}^{n-1} * \sum_{j=i+1}^{n} \operatorname{sign}\left(X_{j}-X_{i}\right)
$$

Where $X_{i}$ and $X_{j}$ are the sequential data in the series and $n$ is the size of the data series.

Where $\mathrm{j}>\mathrm{I}$ and $\mathrm{i}=1,2,3, \ldots, \mathrm{n}^{-1} \mathrm{k}=2,3,4, \ldots, \mathrm{n}$, and $\mathrm{n}$ is the number of data $\operatorname{sign}\left(\mathrm{X}_{\mathrm{j}}-\mathrm{X}_{\mathrm{i}}\right)$ is calculated by (Eq. 17). 


$$
\operatorname{sign}\left(X_{j}-X_{i}\right)= \begin{cases}+1 & \text { if }\left(X_{j}-X_{i}\right)>0 \\ 0 & \text { if }\left(X_{j}-X_{i}\right)=0 \\ -1 & \text { if }\left(X_{j}-X_{i}\right)<0\end{cases}
$$

The variance $S$ is calculated by (Eq. 18).

$$
\operatorname{var}(S)=\frac{S(n-1)(2 n+5)-\sum_{p=1}^{q} t_{p}\left(t_{p}-1\right)\left(2 t_{p}+5\right)}{18}
$$

Where

$\mathrm{q}$ is the number of tied groups in the dataset,

$t_{p}$ is the number of data in the $p^{\text {th }}$ tied group,

$\mathrm{n}$ is the total number of data in the time series.

A positive value of $S$ indicates that an increasing and negative value of $S$ is decreasing ternd of time series data of the candidate station.

The standardized Mann-Kendall test statistics is calculated by (Eq. 19).

$$
Z= \begin{cases}\frac{S-1}{\sqrt{\operatorname{var}(S)}} & \text { if } S>0 \\ 0 & \text { if } S=0 \\ \frac{S+1}{\sqrt{\operatorname{var}(S)}} & \text { if } S<0\end{cases}
$$

\section{Results and Discussion}

3.1. Comparison of Missing Estimation Method's

The ability of each missing estimation technique was evaluated using the statistical metrics of RSR, NSE, and PBIAS. Table 2 and Table 3 show the performances of each missing method at 20- and 40-kilometer radius of influence and different levels of missing percentage. The MLR and MICE methods gave the best results for all statistical performance measures over all stations. Alternatively, the Modified inverse distance method (IDWM $\mathrm{E \& D}_{\mathrm{E} 3}$ ) presented lower values of RMSE, PBIAS and higher NSE.

The CCWM, normal IDWM and modified versions of IDWM such as IDWM C\&D, IDWM $_{\text {E\&D1 }}$ and IDWM E\&D2 $_{\text {. }}$ presented higher biases in RMSE and PBIAS and lower NSE. As long as the percent of missing increases, the model performance tends to decrease for both radiuses of influence (a summary of the results is in Appendix A). Similar evaluation was observed in (Radi et al., 2015; El Kasri et al., 2018) to represent different cases of missing percentages of rainfall data and evaluate the performance of the missing estimation methods. 
1 Table 2 Performance evaluation of missing estimation techniques at 40-kilometer radius of influence for Arata Stations (values in bold indicated the lowest value

2 comparing to the others)

\begin{tabular}{|c|c|c|c|c|c|c|c|c|c|c|c|c|c|c|c|}
\hline \multicolumn{16}{|c|}{ Percent of Missed and Evaluation Metrics } \\
\hline \multirow[t]{3}{*}{ METHODS } & \multicolumn{3}{|l|}{$5 \%$} & \multicolumn{3}{|l|}{$10 \%$} & \multicolumn{3}{|l|}{$15 \%$} & \multicolumn{3}{|l|}{$20 \%$} & \multicolumn{3}{|l|}{$25 \%$} \\
\hline & RMSE & NSE & PBIAS & RMSE & NSE & PBIAS & RMSE & NSE & PBIAS & RMSE & NSE & PBIAS & RMSE & NSE & PBIAS \\
\hline & \multicolumn{15}{|c|}{ Arata Station } \\
\hline IDWM & 6.75 & -1.39 & 44.42 & 7.97 & -2.33 & 69.91 & 13.69 & -8.83 & 164.64 & 14.59 & -10.17 & 190.46 & 16.68 & -13.61 & 239.20 \\
\hline IDWM $_{C \& D}$ & 7.14 & -1.68 & 31.99 & 8.40 & -2.70 & 42.44 & 14.44 & -9.94 & 63.47 & 15.47 & -11.56 & 66.88 & 17.69 & -15.42 & 71.68 \\
\hline CCWM & 7.03 & -1.59 & 46.68 & 8.44 & -2.74 & 75.62 & 14.35 & -9.81 & 174.44 & 15.46 & -11.54 & 203.68 & 17.48 & -15.04 & 252.95 \\
\hline IDWM $_{\mathrm{E} \& \mathrm{D} 1}$ & 3.37 & 0.40 & 21.18 & 4.17 & 0.09 & 35.18 & 7.09 & -1.64 & 82.81 & 6.92 & -1.51 & 88.51 & 8.03 & -2.38 & 114.92 \\
\hline IDWM $_{\mathrm{E} \& \mathrm{D} 2}$ & 1.66 & 0.85 & 8.44 & 2.44 & 0.69 & 16.23 & 3.85 & 0.22 & 38.10 & 2.92 & 0.55 & 32.61 & 3.91 & 0.20 & 46.95 \\
\hline IDWM $_{\mathrm{E} \& \mathrm{D} 3}$ & 1.33 & 0.91 & 5.34 & 2.16 & 0.75 & 11.62 & 3.23 & 0.45 & 27.23 & 2.11 & 0.77 & 18.97 & 3.27 & 0.44 & 30.40 \\
\hline MLR & 0.48 & 0.99 & 2.60 & 0.66 & 0.98 & -0.02 & 0.95 & 0.95 & -0.97 & 0.94 & 0.95 & 1.81 & 0.80 & 0.97 & 3.76 \\
\hline MICE & 0.62 & 0.98 & 1.98 & 0.72 & 0.97 & 0.84 & 1.45 & 0.89 & 3.08 & 1.31 & 0.91 & -1.53 & 1.24 & 0.92 & 2.35 \\
\hline
\end{tabular}

3 Table 3 Performance evaluation of missing estimation techniques at a 20-kilometer radius of influence for Arata stations (values in bold indicate the lowest value 4 compared to the others)

\begin{tabular}{|c|c|c|c|c|c|c|c|c|c|c|c|c|c|c|c|}
\hline \multicolumn{16}{|c|}{ Percent of Missed and Evaluation Metrics } \\
\hline \multirow[t]{3}{*}{ METHODS } & \multicolumn{3}{|l|}{$5 \%$} & \multicolumn{3}{|l|}{$10 \%$} & \multicolumn{3}{|l|}{$15 \%$} & \multicolumn{3}{|l|}{$20 \%$} & \multicolumn{3}{|l|}{$25 \%$} \\
\hline & RMSE & NSE & PBIAS & RMSE & NSE & PBIAS & RMSE & NSE & PBIAS & RMSE & NSE & PBIAS & RMSE & NSE & PBIAS \\
\hline & \multicolumn{15}{|c|}{ Arata Station } \\
\hline IDWM & 6.64 & -1.31 & 43.60 & 7.83 & -2.22 & 68.53 & 13.46 & -8.51 & 161.68 & 14.31 & -9.75 & 186.67 & 16.38 & -13.09 & 234.74 \\
\hline IDWM $_{C \& D}$ & 7.05 & -1.61 & 31.68 & 8.29 & -2.60 & 42.06 & 14.25 & -9.66 & 63.15 & 15.25 & -11.20 & 66.53 & 17.45 & -14.98 & 71.39 \\
\hline CCWM & 7.22 & -1.73 & 47.53 & 8.47 & -2.77 & 74.28 & 14.58 & $\begin{array}{l}- \\
10.15\end{array}$ & 175.29 & 15.63 & -11.82 & 203.89 & 17.89 & -15.79 & 255.61 \\
\hline IDWM $_{E \& D 1}$ & 3.24 & 0.45 & 20.19 & 4.02 & 0.15 & 33.59 & 6.82 & -1.44 & 79.27 & 6.59 & -1.28 & 84.01 & 7.68 & -2.09 & 109.59 \\
\hline IDWM $_{\mathrm{E} \& \mathrm{D} 2}$ & 1.62 & 0.86 & 8.07 & 2.41 & 0.70 & 15.63 & 3.77 & 0.26 & 36.77 & 2.81 & 0.59 & 30.92 & 3.82 & 0.24 & 44.95 \\
\hline IDWM $_{E \& D 3}$ & 1.32 & 0.91 & 5.24 & 2.16 & 0.76 & 11.46 & 3.21 & 0.46 & 26.89 & 2.09 & 0.77 & 18.53 & 3.26 & 0.44 & 29.89 \\
\hline MLR & 0.43 & 0.99 & 2.25 & 0.73 & 0.97 & -0.59 & 1.07 & 0.94 & -1.60 & 0.88 & 0.96 & 0.54 & 0.91 & 0.96 & 2.24 \\
\hline MICE & 0.55 & 0.98 & 2.05 & 0.94 & 0.95 & -1.00 & 1.23 & 0.92 & -2.08 & 1.25 & 0.92 & -0.94 & 1.31 & 0.91 & 3.68 \\
\hline
\end{tabular}


The normal inverse distance weighted method (IDWM) is modified by the inclusion of the elevation difference between the target and neighboring stations and the exponent of value of "a", for distances which range from one to three. As the result is shown in Table 4, the inclusion of an elevation difference and gradually increasing the exponent values for distance, significantly lowered the error in terms of RMSE, PBIAS, and increased the NSE of the inverse distance weighted method. The inclusion of an elevation difference between the stations significantly increased the performance of normal IDWM. For example, the comparison between IDWM and the modified version IDWME\&D1 has shown that the RMSE is reduced from 1.52 (IDWM) to 0.74 (IDWME\&D1), PBIAS from 43.6 (IDWM) to 20.19 (IDWME\&D1) and the NSE is increased from-1.31 (IDWM) to 0.45 (IDWME\&D1) at $5 \%$ of missing percentage and a 20-kilo meter radius of influence for Arata station. This is also true for other stations that are considered in this study (Appendix B). A similar study was done on the impact of elevation on the performance of the missing estimation method (Barrios et al., 2018).

The other value added for IDWM is, the value of the exponent for the Euclidian distance between the target and neighboring stations. Gradually increasing the exponent value from 1 to 3 increases the performance of IDWM. For exponent values of $a=1$ and $a=3$, the performance of the models was significantly improved (see Table 4 as an example for Arata station and Appendix for all stations). Generally, accounting for the elevation difference and increasing the exponent value " $\mathrm{a}=3$ " can increase the performance of the inverse distance weighted method by lowering the error of RSR and PBIAS and increasing the precision (NSE). However, as the assessment results have been shown in Table 4 and Appendix, both radiuses of influence have no significant difference on the IDWM and its version.

Table 4 Impact of the exponent value of "a" on the spatial distance of the Inverse Distance weighted method for Arata station

\begin{tabular}{|c|c|c|c|c|c|c|c|c|}
\hline \multicolumn{9}{|c|}{ Performance evaluation based on Root Mean Square Error (RMSE) } \\
\hline \multirow{3}{*}{$\begin{array}{l}\text { Missing } \\
\text { percentage }\end{array}$} & \multicolumn{2}{|c|}{ IDWM } & \multicolumn{2}{|c|}{$\mathrm{IDWM}_{\mathrm{E} \& \mathrm{D}}{ }^{\mathrm{a}}$ for $\mathrm{a}=1$} & \multicolumn{2}{|c|}{ IDWM $_{E \& D}{ }^{a}$ for $a=2$} & \multicolumn{2}{|c|}{$I_{D W M} \& D^{a}$ for $a=3$} \\
\hline & \multicolumn{8}{|c|}{ Radius of influence } \\
\hline & $20 \mathrm{Km}$ & $40 \mathrm{Km}$ & $20 \mathrm{Km}$ & $40 \mathrm{Km}$ & $20 \mathrm{~km}$ & $40 \mathrm{Km}$ & $20 \mathrm{Km}$ & $40 \mathrm{Km}$ \\
\hline 5 & 1.52 & 1.55 & 0.74 & 0.77 & 0.37 & 0.38 & 0.30 & 0.30 \\
\hline 10 & 1.79 & 1.83 & 0.92 & 0.96 & 0.55 & 0.56 & 0.49 & 0.50 \\
\hline 15 & 3.08 & 3.14 & 1.56 & 1.62 & 0.86 & 0.88 & 0.74 & 0.74 \\
\hline 20 & 3.28 & 3.34 & 1.51 & 1.59 & 0.64 & 0.67 & 0.48 & 0.48 \\
\hline 25 & 3.75 & 42.92 & 1.76 & 1.84 & 0.87 & 0.90 & 0.75 & 0.75 \\
\hline \multicolumn{9}{|c|}{ Nash Sutcliffe efficiency $\left(\mathrm{NS}_{\mathrm{E}}\right)$} \\
\hline 5 & -1.31 & -1.39 & 0.45 & 0.40 & & 0.85 & 0.91 & 0.91 \\
\hline 10 & -2.22 & -2.33 & 0.15 & 0.09 & 0.70 & 0.69 & 0.76 & 0.75 \\
\hline 15 & -8.51 & -8.83 & -1.44 & -1.64 & 0.26 & 0.22 & 0.46 & 0.45 \\
\hline 20 & -9.75 & -10.17 & -1.28 & -1.51 & 0.59 & 0.55 & 0.77 & 0.77 \\
\hline 25 & -13.09 & -13.61 & -2.09 & -2.38 & 0.24 & 0.20 & 0.44 & 0.44 \\
\hline \multicolumn{9}{|c|}{ Percent of Bias (PBIAS) } \\
\hline 5 & 43.60 & 44.42 & 20.19 & 21.18 & 8.07 & 8.44 & 5.24 & 5.34 \\
\hline 10 & 68.53 & 69.91 & 33.59 & 35.18 & 15.63 & 16.23 & 11.46 & 11.62 \\
\hline 15 & 161.68 & 164.64 & 79.27 & 82.81 & 36.77 & 38.10 & 26.89 & 27.23 \\
\hline 20 & 186.67 & 190.46 & 84.01 & 88.51 & 30.92 & 32.61 & 18.53 & 18.97 \\
\hline 25 & 234.74 & 239.20 & 109.59 & 114.92 & 44.95 & 46.95 & 29.89 & 30.40 \\
\hline
\end{tabular}

As shown in Table 3 and Table 4 for Arata station and in the Appendix for the rest of the stations, the performance of the missing estimation method has decreased as the missing percentage has increased over all stations. The MLR, MICE, and IDWM $\mathrm{E \& D}_{3}$ performed very well for most stations at all levels of missing percentages compared to other missing estimation techniques. For example, the IDWM method presented the poorest performance for Arata station, which resulted in 16.68 RMSE, 239 PBIAS and-13 $\mathrm{NS}_{\mathrm{E}}$. Similarly, for the rest stations, as long as the missing 
percentages are increasing, the model performance tends to decrease to estimate accurately the missed values of the target station (Appendix). This is agreed with the studies by Program (2001) and El Kasri et al. (2018). The performance of the missing estimation methods was reduced as the missing values increased. Other studies have shown that the power and precision of statistical research methods can be affected as the missing percentages increase (Pigott, 201; Piazza, 2011; Houari et al., 2014; Schmitt et al., 2015; Gao et al., 2018). This may result in uncertain flood estimates and imperfect flood management decisions and intervention mechanisms (Blackburn et al., 2018).

\subsection{Identifying of the Best Method}

To identify the best infilling technique, the multicriteria decision with compromise programing (CP) method was used. Here the result for Arata station has been shown for demonstration. Among the three performance indicators, PBIAS (0.498) has a significant weight on the ranking of the missing estimation methods, followed by RMSE (0.421) and $\mathrm{NS}_{\mathrm{E}}$ (0.08). Equations 11-15 were coded in Excel 2016 and the entropy, degree of diversification, normalized weight and payoff matrix (Pij), LP metrics were calculated subsequently. Then, based on the minimum values of $L_{P}$ metrics, each missing estimation method was ranked. As the results in Table 5 and 6 showed for Arata station, the MLR, MICE, and IDWM $M_{\mathrm{E} \& 3}$ were ranked as $1^{\text {st }}, 2^{\text {nd }}$, and $3^{\text {rd }}$ best methods respectively. The normal IDWM and CCWM are ranked $7^{\text {th }}$ and $8^{\text {th }}$. Similarly, for the rest stations, the results of the best of three methods are summarized in Appendix A. A similar study has been conducted by Radi et al., (2015) on the performance of missing estimation methods, and the analysis of variance (anova) was used to identify the best method. Raju et al., (2016), applied the compromise programing method to select the best global climate models for India.

Table 5 Multi-criteria decision method for Arata Station compromise programming within a 40-kilometer radius of influence

\begin{tabular}{|l|l|l|l|l|l|l|l|l|l|l|}
\hline \multicolumn{10}{|c|}{ Compromise programming result } \\
\hline Methods & Lp & Rank & Lp & Rank & Lp & Rank & Lp & Rank & Lp & Rank \\
& & & & & & & & & \multicolumn{2}{c|}{$20 \%$} \\
\hline IDWM & 7.837 & 7 & 23.997 & 7 & 150.309 & 7 & 287.062 & 7 & 388.279 & 7 \\
\hline IDWMC\&D & 4.034 & 6 & 9.056 & 6 & 26.040 & 5 & 41.189 & 5 & 45.846 & 5 \\
\hline CCWM & 9.382 & 8 & 28.187 & 8 & 175.437 & 8 & 340.488 & 8 & 456.425 & 8 \\
\hline IDWME\&D1 & 1.522 & 5 & 5.830 & 5 & 42.451 & 6 & 67.395 & 6 & 103.858 & 6 \\
\hline IDWME\&D2 & 0.186 & 4 & 1.345 & 4 & 15.869 & 4 & 18.820 & 4 & 38.646 & 4 \\
\hline IDWME\&D3 & 0.065 & 3 & 0.783 & 3 & 12.362 & 3 & 13.843 & 3 & 31.082 & 3 \\
\hline MLR & 0.007 & 1 & 0.152 & 1 & 8.449 & 1 & 11.090 & 1 & 25.211 & 1 \\
\hline MICE & 0.009 & 2 & 0.155 & 2 & 8.463 & 2 & 11.122 & 2 & 25.280 & 2 \\
\hline
\end{tabular}

Table 6 Multi-criteria decision method for Arata Station compromise programming within a 20-kilometer radius of influence

\begin{tabular}{|l|l|l|l|l|l|l|l|l|l|l|}
\hline \multicolumn{10}{|c|}{ Compromise programming result } \\
\hline & $5 \%$ & $10 \%$ & \multicolumn{1}{l|}{$15 \%$} & $20 \%$ & $25 \%$ & Rank \\
\hline Methods & Lp & Rank & Lp & Rank & Lp & Rank & Lp & Rank & Lp & \\
\hline IDWM & 5.998 & 7 & 20.759 & 7 & 115.223 & 7 & 207.711 & 7 & 301.108 & 7 \\
\hline IDWMC\&D & 3.039 & 6 & 7.701 & 6 & 17.467 & 5 & 25.707 & 5 & 27.658 & 5 \\
\hline CCWM & 6.650 & 8 & 24.281 & 8 & 129.482 & 8 & 237.888 & 8 & 329.490 & 8 \\
\hline IDWME\&D1 & 1.245 & 5 & 5.267 & 5 & 28.727 & 6 & 43.936 & 6 & 66.303 & 6 \\
\hline IDWME\&D2 & 0.150 & 4 & 1.130 & 4 & 5.927 & 4 & 5.623 & 4 & 10.479 & 4 \\
\hline IDWME\&D3 & 0.046 & 3 & 0.585 & 3 & 2.974 & 3 & 1.777 & 3 & 4.197 & 3 \\
\hline MLR & 0.001 & 1 & 0.001 & 1 & 0.003 & 1 & 0.001 & 1 & 0.015 & 1 \\
\hline MICE & 0.002 & 2 & 0.005 & 2 & 0.027 & 2 & 0.005 & 2 & 0.022 & 2 \\
\hline
\end{tabular}


3.5. Quality Assessment for Precipitation Data

3.5.1. Statistical Characteristics of Precipitation

The long-term mean and maximum monthly observed rainfall in the Katar subbasin varied from $58.24 \mathrm{~mm}$ to $87 \mathrm{~mm}$ and $230.6 \mathrm{~mm}$ to $581 \mathrm{~mm}$, and for the Meki subbasin varied from $60 \mathrm{~mm}$ to $85.63 \mathrm{~mm}$ and $292.3 \mathrm{~mm}$ to $489.3 \mathrm{~mm}$ respectively. The standard deviation (SD) varied from 57 to 94.33 and the coefficient of variation (CV) varied from $84.69 \%$ to $108.42 \%$ for the Katar subbasin. Similarly, for the Meki subbasin, SD and CV varied from 62 to 86.23 and $97.32 \%$ to $119.01 \%$, respectively. This presented that there was a great temporal variability of monthly rainfall during 1997-2017 in both subbasins. The highest variations were observed at Adami-tulu and Iteya stations (Table 7).

Table 7 Monthly rainfall statistics for 16 stations from 1983 to 2017 after missing data have been filled

\begin{tabular}{|l|l|l|l|l|l|}
\hline Stations & Minimum $(\mathrm{mm})$ & Maximum $(\mathrm{mm})$ & Average $(\mathrm{mm})$ & SD & CV $(\%)$ \\
\hline Adami-tulu & 0.00 & 435.60 & 68.02 & 80.94 & 119.01 \\
\hline Alem-tena & 0.00 & 392.50 & 70.26 & 78.68 & 111.99 \\
\hline Bui & 0.00 & 353.90 & 81.64 & 82.44 & 100.99 \\
\hline Butajera & 0.00 & 438.00 & 85.63 & 86.23 & 100.71 \\
\hline Ejerse-lele & 0.00 & 348.30 & 72.02 & 79.01 & 109.70 \\
\hline Koshe & 0.00 & 292.30 & 63.74 & 62.03 & 97.32 \\
\hline Meki & 0.00 & 489.30 & 61.43 & 65.23 & 106.19 \\
\hline Ziway & 0.00 & 292.30 & 59.99 & 62.26 & 103.77 \\
\hline Arata & 0.00 & 230.60 & 63.21 & 57.03 & 90.22 \\
\hline Asella & 0.00 & 318.20 & 88.23 & 74.72 & 84.69 \\
\hline Dagaga & 0.00 & 269.70 & 85.07 & 73.72 & 86.66 \\
\hline Iteya & 0.00 & 581.00 & 87.00 & 94.33 & 108.42 \\
\hline Katar-genet & 0.00 & 368.90 & 63.90 & 65.11 & 101.90 \\
\hline Kulumsa & 0.00 & 272.10 & 65.49 & 57.41 & 87.66 \\
\hline Ogolcho & 0.00 & 322.90 & 58.24 & 57.74 & 99.15 \\
\hline Sagure & 0.00 & 406.00 & 62.59 & 58.71 & 93.80 \\
\hline
\end{tabular}

$\mathrm{SD}$ is standard deviation and $\mathrm{CV}$ is coefficient of variation

\subsubsection{Homogeneity Tests}

An absolute homogeneity test was applied using SNHT, Buishand's, Pettit, and Von Neumann tests to check whether the long-term climatological data belongs to the same population with no temporal variation. If any change in the time series was only attributed to a natural occurrence. Based on the hypothesis test for homogeneity, the empirical calculated p-value is at $95 \%$ of the significant level summarized in Table 8 for the Katar and Meki watersheds. Based on the test results, seven stations were homogeneous in the Katar watershed based on the above four tests. However, one (Iteya) station was nonhomogeneous only by the Buishand's test. Similarly, for stations in the Meki watershed, the homogeneity tests were conducted. Except for Butajera station, all stations were homogeneous based on the test results of SNHT, Buishand's, Pettit and Von Neumann tests at 95\% of significant level (Table 9). An extensive examination was carried out on the meta-data and archive information concerning the history of the measurements for both stations. No apparent explanation could be found for the causes of the changes. Based on Wijngaard et al., (2003) classification for homogeneity, 15 stations were classified as useful and only Butajera stations were suspected. Schönwiese and Rapp (1997) and Patakamuri at al. (2020) found similar classification.

Table 8 Calculated P-values for homogeneity testes at alpha $(\alpha)=0.05$ for Ketar sub basin and decision made based on (Wijngaard et al., 2003)

\begin{tabular}{|l|l|c|c|c|c|c|l|}
\hline № & Station's & Pettit & \multicolumn{1}{|c|}{ SNHT } & Buishand's & Von Neumann & $\alpha$-value & Decision \\
\hline 1 & Arata & 0.463 & 0.720 & 0.861 & $<\mathbf{0 . 0 0 0 1}$ & 0.05 & Useful \\
\hline 2 & Asella & 0.203 & 0.647 & 0.949 & $<\mathbf{0 . 0 0 0 1}$ & 0.05 & Useful \\
\hline 3 & Dagaga & 0.759 & 0.653 & 0.668 & $<\mathbf{0 . 0 0 0 1}$ & 0.05 & Useful \\
\hline 4 & Iteya & 0.148 & 0.092 & $\mathbf{0 . 0 1 7}$ & $<\mathbf{0 . 0 0 0 1}$ & 0.05 & Useful \\
\hline 5 & Katar-genet & 0.489 & 0.788 & 0.381 & $<\mathbf{0 . 0 0 0 1}$ & 0.05 & Useful \\
\hline 6 & Kulumsa & 0.146 & 0.651 & 0.991 & $<\mathbf{0 . 0 0 0 1}$ & 0.05 & Useful \\
\hline 7 & Ogolcho & 0.635 & 0.782 & 0.897 & $<\mathbf{0 . 0 0 0 1}$ & 0.05 & Useful \\
\hline 8 & Sagure & 0.673 & 0.113 & 0.712 & $<\mathbf{0 . 0 0 0 1}$ & 0.05 & Useful \\
\hline
\end{tabular}


Table 9 Calculated P-values for homogeneity tested methods at alpha $(\alpha)=0.05$ for Meki sub basin and decision made based on (Wijngaard et al., 2003)

\begin{tabular}{|l|l|l|l|l|l|l|l|}
\hline № & Station's & Pettit & SNHT & Buishand's & Von Neumann & $\alpha$-value & Decision \\
\hline 1 & Adami-tulu & 0.130 & 0.094 & 0.136 & $<\mathbf{0 . 0 0 0 1}$ & 0.05 & Useful \\
\hline 2 & Alem-tena & 0.184 & 0.895 & 0.976 & $<\mathbf{0 . 0 0 0 1}$ & 0.05 & Useful \\
\hline 3 & Bui & 0.345 & 0.520 & 0.235 & $<\mathbf{0 . 0 0 0 1}$ & 0.05 & Useful \\
\hline 4 & Butajera & $\mathbf{0 . 0 0 0}$ & $\mathbf{0 . 0 0 1}$ & $\mathbf{0 . 0 0 1}$ & $<\mathbf{0 . 0 0 0 1}$ & 0.05 & Suspect \\
\hline 5 & Ejerse-lele & 0.444 & 0.879 & 0.941 & $<\mathbf{0 . 0 0 0 1}$ & 0.05 & Useful \\
\hline 6 & Koshe & 0.738 & 0.847 & 0.496 & $<\mathbf{0 . 0 0 0 1}$ & 0.05 & Useful \\
\hline 7 & Meki & 0.174 & 0.997 & 0.992 & $\mathbf{0 . 0 0 0 1}$ & 0.05 & Useful \\
\hline 8 & Ziway & 0.927 & 0.906 & 0.596 & $\mathbf{0 . 0 0 0 1}$ & 0.05 & Useful \\
\hline
\end{tabular}

3.6. Trend Analysis

Each chosen station has 17 series (12 months, four seasons, and an annual series), for a total of 255 time series data from 15 meteorological stations. Monthly, seasonal and annual monotonic upward or downward trends in rainfall were assessed for each station independently using the Mann-Kendall trend test, and the magnitude of the trend was estimated using the Sone's slope for the time series data of 1997-2017.

\subsubsection{Monthly trend analysis}

As shown in Table 10, the rainfall had a combination of increasing and decreasing trends at all stations. There was a statistically significant decreasing trend for Dagag station for the month of January with a magnitude of $1.52 \mathrm{~mm} /$ month. For Iteya station, the rainfall amount shows a decreasing trend for the months of June, August, and October with a magnitude of $2.15,5.05$, and $3.06 \mathrm{~mm}$, respectively. At Kulumsa station, there was a significant increasing trend in rainfall for the months of May and September, with a magnitude of 4.38 and $3.13 \mathrm{~mm}$, respectively. Similarly, Bui station showed a statistically significant decreasing trend with a magnitude of $0.83 \mathrm{~mm}$. At Butajera station for the months of March, April, August and October, there was a significant decreasing trend with a magnitude of $6.82,4.54,5.7$ and $4.07 \mathrm{~mm}$, respectively. For Ejerese-lele station, there was a significant increase in monthly rainfall during September with a magnitude of $2.63 \mathrm{~mm}$. However, the rest station has shown no statistically significant increasing or decreasing trends in monthly rainfall.

\subsubsection{Seasonal and Annual Trend Analysis}

Seasonal trend analysis was performed and considered the sum of three consecutive months, such as for spring (March, April, and May), summer (June, July, and August), and autumn (September, October, and November) and for winter (December, January, and February). Annual trend analysis was performed for a time series of rainfall data from 19832017. As a trend, analysis results are stated in Table 11, both increasing (positive) and decreasing (negative) in the seasonal and annual rainfall. A decreasing trend in seasonal rainfall was observed for Iteya station during summer $(10.65 \mathrm{~mm})$ and autumn $(11.48 \mathrm{~mm})$. Dagaga station had a statistically significant decrease in seasonal rainfall during autumn $(6.41 \mathrm{~mm})$. Similarly, Butajera showed a significant decreasing trend during spring $(14.75 \mathrm{~mm})$ and autumn $(9.9 \mathrm{~mm})$. The annual based trend analysis resulted in increasing and decreasing trends in the annual rainfall series. Iteya and Butajera stations have shown statistically significant decreasing trends with a magnitude of $34.84 \mathrm{~mm} / \mathrm{year}$ and $40.36 \mathrm{~mm} /$ year respectively. 
113 Table 10 Monthly based trend analysis for meteorological stations in Katar and Meki watersheds at alpha $(\alpha=0.05)$

\begin{tabular}{|c|c|c|c|c|c|c|c|c|c|c|c|c|c|}
\hline Stations & Tests & Jan & Feb & Mar & Apr & May & Jun & Jul & Aug & Sep & Oct & Nov & Dec \\
\hline \multirow[t]{2}{*}{ Arata } & Z-Value & -0.65 & -0.88 & -0.57 & -0.97 & 0.63 & -0.33 & 1.09 & 0.75 & -0.09 & -1.27 & -1.32 & -0.14 \\
\hline & Sen's slope & 0.00 & -0.28 & -0.85 & -1.49 & 1.05 & -0.66 & 2.51 & 1.35 & -0.05 & -0.84 & -0.39 & 0.00 \\
\hline \multirow[t]{2}{*}{ Asella } & Z-Value & -0.65 & -0.27 & -0.09 & -1.00 & 1.60 & -1.66 & 0.03 & 0.27 & 1.66 & -1.24 & -0.24 & -1.28 \\
\hline & slope & 0.00 & -0.36 & -0.38 & -2.62 & 4.89 & -2.35 & -0.03 & 0.71 & 2.32 & -2.82 & -0.11 & -0.03 \\
\hline \multirow[t]{2}{*}{ Dagaga } & Z-Value & $-2.52^{*}$ & 0.76 & -1.66 & -0.51 & 1.45 & -0.75 & -0.15 & -0.45 & -0.88 & -1.81 & -0.45 & -1.34 \\
\hline & Sen's slope & -1.52 & 0.17 & -2.99 & -1.09 & 2.92 & -1.58 & -0.42 & -0.67 & -1.32 & -2.99 & -0.15 & -0.19 \\
\hline \multirow[t]{2}{*}{ Iteya } & Z-Value & $-2.30^{*}$ & 0.09 & -1.57 & -1.78 & 1.36 & -1.84 & -1.12 & $-1.96^{*}$ & -2.08 & $-1.42^{*}$ & 0.00 & -0.38 \\
\hline & Sen's slope & -2.15 & 0.00 & -2.77 & -2.56 & 1.51 & -2.65 & -2.37 & -5.03 & -5.88 & -3.06 & 0.00 & 0.00 \\
\hline \multirow[t]{2}{*}{ Ketar-genet } & Z-Value & -1.22 & 1.00 & 0.42 & -0.15 & -0.12 & -0.51 & 0.18 & 1.72 & 1.12 & -0.73 & 0.60 & 0.71 \\
\hline & Sen's slope & -0.11 & 0.18 & 0.59 & -0.17 & -0.28 & -1.02 & 0.26 & 4.57 & 1.49 & -0.87 & 0.00 & 0.00 \\
\hline \multirow[t]{2}{*}{ Kulumsa } & Z-Value & -1.48 & 0.36 & -0.73 & -0.51 & $2.33^{*}$ & -1.48 & 0.82 & -0.91 & $2.57^{*}$ & -1.15 & 0.03 & -0.43 \\
\hline & Sen's slope & -0.46 & 0.07 & -1.31 & -1.04 & 4.38 & -2.02 & 1.97 & -1.50 & 3.13 & -2.29 & 0.00 & 0.00 \\
\hline \multirow[t]{2}{*}{ Ogolcho } & Z-Value & -1.28 & 0.34 & -0.60 & -0.15 & 1.36 & -0.45 & -0.39 & 0.15 & 0.63 & -0.91 & 0.16 & -0.29 \\
\hline & Sen's slope & 0.00 & 0.00 & -1.21 & -0.16 & 2.00 & -0.42 & -0.60 & 0.22 & 0.88 & -0.94 & 0.00 & 0.00 \\
\hline \multirow[t]{2}{*}{ Sagure } & Z-Value & -1.55 & 0.57 & -2.00 & -0.39 & -0.94 & -1.42 & -1.18 & 0.70 & 1.91 & 0.73 & 1.54 & $-2.22^{*}$ \\
\hline & Sen's slope & -0.37 & 0.17 & -2.70 & -0.49 & -1.25 & -2.24 & -1.03 & 0.46 & 1.24 & 0.45 & 0.31 & -0.53 \\
\hline \multirow[t]{2}{*}{ Adami-tulu } & Z-Value & -1.11 & 0.66 & -0.36 & -1.21 & 0.79 & 0.27 & 1.24 & -0.45 & -0.12 & -0.82 & 1.26 & -0.61 \\
\hline & Sen's slope & 0.00 & 0.00 & -0.26 & -2.69 & 1.70 & 0.70 & 2.87 & -1.54 & -0.37 & -1.41 & 0.00 & 0.00 \\
\hline \multirow[t]{2}{*}{ Alem-tena } & Z-Value & -1.42 & -0.45 & -0.30 & -1.90 & $2.87^{*}$ & 0.39 & 0.45 & 0.03 & 1.30 & -1.65 & 0.67 & -0.10 \\
\hline & slope & -0.10 & 0.00 & -0.62 & -4.27 & $6.91^{*}$ & 0.68 & 2.11 & 0.09 & 2.86 & -1.37 & 0.00 & 0.00 \\
\hline \multirow[t]{2}{*}{ Bui } & Z-Value & $-2.18^{*}$ & -0.47 & -0.21 & -0.12 & 0.88 & -1.18 & -1.30 & 0.06 & 0.51 & -1.61 & -0.34 & -1.01 \\
\hline & Sen's slope & -0.83 & 0.00 & -0.56 & -0.21 & 1.70 & -2.07 & -3.25 & 0.16 & 0.88 & -2.24 & 0.00 & 0.00 \\
\hline \multirow[t]{2}{*}{ Butajera } & Z-Value & -0.61 & 0.00 & $-2.78^{*}$ & $-2.02^{*}$ & -0.82 & -1.90 & -0.39 & $-2.02^{*}$ & -1.72 & $-3.14^{*}$ & -0.68 & -0.10 \\
\hline & Sen's slope & -0.29 & 0.03 & -6.82 & -4.54 & -1.58 & -5.88 & -1.12 & -5.70 & -4.23 & -4.07 & -0.04 & 0.00 \\
\hline \multirow[t]{2}{*}{ Ejerse-lele } & Z-Value & $-2.03^{*}$ & -0.03 & -0.27 & -0.88 & 1.81 & -0.45 & -0.76 & -0.67 & $2.63^{*}$ & -1.28 & -0.46 & 0.45 \\
\hline & Sen's slope & -0.48 & 0.00 & -0.62 & -1.73 & 2.70 & -0.56 & -2.06 & -1.21 & 3.34 & -0.62 & 0.00 & 0.00 \\
\hline \multirow[t]{2}{*}{ Koshe } & Z-Value & 0.10 & -0.73 & -1.18 & 0.70 & -1.36 & 0.15 & -1.24 & -0.03 & -0.94 & 1.38 & 1.24 & -0.63 \\
\hline & Sen's slope & 0.00 & -1.17 & -1.51 & 2.21 & -2.97 & 0.31 & -2.87 & -0.26 & -1.72 & 0.00 & 0.00 & -7.26 \\
\hline \multirow[t]{2}{*}{ Meki } & Z-Value & -1.05 & -0.90 & -0.57 & -1.54 & 1.72 & 0.48 & 0.27 & -1.30 & 1.42 & -0.66 & 0.98 & 0.64 \\
\hline & Sen's slope & 0.00 & -0.09 & -0.84 & -2.50 & 2.39 & 0.85 & 0.63 & -3.24 & 1.54 & 0.00 & 0.00 & 0.00 \\
\hline Ziway & Z-Value & -0.77 & 0.25 & -1.66 & -1.18 & 1.15 & -0.45 & 0.51 & -0.63 & -0.39 & -0.70 & 0.94 & 0.83 \\
\hline
\end{tabular}

$*$ Represents significant at $95 \%$ confidence level with the corresponding critical value of 1.96 
Table 11 Seasonal and annual rainfall trend analysis for the Katar and Meki watersheds

\begin{tabular}{|l|l|l|l|l|l|l|l|l|l|l|}
\hline & Annual & \multicolumn{3}{l}{ Spring } & \multicolumn{1}{l}{ Summer } & Autumn & \multicolumn{2}{l|}{ Winter } \\
\hline Stations & MK & SS & MK & SS & MK & SS & MK & SS & MK & SS \\
\hline Arata & -0.69 & -3.10 & 0.03 & -0.12 & 1.06 & 2.97 & -1.75 & -4.93 & -0.85 & -0.75 \\
\hline Asella & -0.09 & -0.61 & 0.15 & 1.11 & 0.03 & 0.01 & -0.63 & -2.69 & -0.75 & -1.61 \\
\hline Kulumsa & 0.27 & 1.17 & 0.27 & 1.04 & -0.69 & -1.23 & 0.03 & -0.14 & -0.33 & -0.37 \\
\hline Ogolcho & 0.03 & 0.26 & 0.45 & 1.27 & -0.15 & -0.52 & -0.09 & -0.33 & -0.52 & -0.16 \\
\hline Sagure & -1.15 & -6.09 & -1.63 & -4.14 & -1.12 & -2.43 & 1.72 & 2.43 & -0.94 & -0.81 \\
\hline Dagaga & -1.78 & -10.45 & -0.03 & -0.23 & -0.21 & -0.97 & $\mathbf{- 2 . 3 9 ^ { * }}$ & $\mathbf{- 6 . 4 1}$ & -1.48 & -1.65 \\
\hline Katar-genet & 0.33 & 2.41 & -0.27 & -0.79 & 0.57 & 4.31 & 0.03 & 0.16 & 0.48 & 0.12 \\
\hline Iteya & $\mathbf{- 2 . 8 1 ^ { * }}$ & -34.84 & -0.63 & -2.22 & $\mathbf{- 2 . 0 8}$ & $\mathbf{- 1 0 . 7}$ & $\mathbf{- 3 . 0 5}$ & $\mathbf{- 1 1 . 5}$ & -1.60 & -2.57 \\
\hline Adami-tulu & 0.21 & 3.81 & -0.63 & -1.57 & 0.03 & -0.10 & -0.82 & -2.81 & -0.21 & -0.29 \\
\hline Alem-tena & 1.06 & 4.50 & 0.88 & 2.91 & 0.33 & 1.62 & 0.69 & 1.11 & -0.42 & -0.28 \\
\hline Bui & -1.00 & -9.84 & 0.94 & 3.84 & -1.18 & -7.25 & -1.66 & -2.85 & -1.69 & -2.43 \\
\hline Butajera & $\mathbf{- 2 . 2 0}$ & $\mathbf{- 4 0 . 4}$ & $\mathbf{- 2 . 9 9}$ & $\mathbf{- 1 4 . 8}$ & -0.94 & -8.73 & $\mathbf{- 3 . 0 5}$ & $\mathbf{- 9 . 9 0}$ & -1.66 & -4.07 \\
\hline Ejerse-lele & -0.45 & -2.67 & 0.21 & 1.37 & -0.33 & -1.31 & 0.82 & 2.09 & -1.13 & -1.79 \\
\hline Koshe & -0.63 & -7.26 & -0.39 & -1.07 & -0.45 & -2.49 & -0.69 & -1.79 & -0.06 & -0.34 \\
\hline Meki & 0.21 & 2.37 & -0.27 & -0.57 & 0.03 & 0.45 & 0.09 & 0.31 & -0.85 & -0.82 \\
\hline Ziway & -0.51 & -3.42 & -0.94 & -3.04 & 0.03 & 0.03 & -0.45 & -1.72 & 0.30 & 0.54 \\
\hline
\end{tabular}

$116 *$ Represents significant at $95 \%$ confidence level with the corresponding critical value of 1.96.

\section{Conclusion}

In this study, the performance of eight missing estimation methods has been evaluated using three statistical metrics: RMSE, NSE, and PBIAS. Specifically, we purposely assigned missing (NA) for the CHRIPS dataset at 5\%, 10\%, $15 \%, 20 \%$, and $25 \%$ and examined two radiuses of influence (20 and 40 kilo meter) between the target and neighboring stations. The Multicriteria decision method (MCDM) of compromise programing (CP) was used to identify the best missing imputation technique for each station. MLR and MICE methods were selected as the best approach for missing infilling for the most stations. And an alternative, modified version of IDWM based on spatial distance and elevation difference (IDWME\&D3) preferred as the third option.

The ability of IDWM was significantly improved by the inclusion of the elevation difference and gradually increasing exponent value for "a $=3$ " for the distance between the target and neighboring stations. The study results showed that the performance of all missing estimation techniques was significantly decreased as the percentage of missing data increased. A study for a homogeneity test for time series data has shown that, except for one station, the majority of stations are homogeneous and they are useful. Monthly, seasonal, and annual trends have been observed in decreasing Dagaga and Iteya and an increasing trend in Kulumsa stations of the Katar subbasin. In the same way, Bui and Butajera have shown a significant decreasing trend in monthly rainfall and Ejerese-lele station has shown a significant increase in monthly rainfall in the Meki subbasin. However, the rest stations have shown no significant increasing or decreasing trends in rainfall.

\section{Statements \& Declarations}

Conflict of interest: The authors declare that they have no competing interests regarding this article.

Funding: This work was supported by the Water Security and Sustainable Development Hub funded by the UK Research and Innovation's Global Challenges Research Fund (GCRF) [grant number: ES/S008179/1].

Author Contribution: All authors contributed to the study conception and design. Material preparation, data collection, analysis and writing original draft of the manuscript Sisay Kebede Balcha, first draft of the manuscript editing and review Taye Alemayehu Hulluka, and supervision Taye Alemayehu Hulluka; Adane Abebe Awass and Amare Bantider. All authors have read and approved the final manuscript.

Availability of data: All datasets, raw or preprocessed, are available upon request from the corresponding author. However, permission is required for observed data collected from National Meteorology Agency of Ethiopia. 


\section{Declarations (ethics) \\ $>$ Consent to participation: Not applicable' for that specific section \\ $>$ Consent to publish: Not applicable' for that specific section}

Ethical Approval: Hereby, I Mr. Sisay Kebede Balcha certainly assure that the manuscript entitled "Comparison and Selection Criterion of Missing Imputation Methods and Quality Assessment of Monthly Rainfall in the Central Refit Valley Lakes Basin of Ethiopia" the following is fulfilled:

1. The research paper is not currently being considered for publication elsewhere.

2. This research paper is the authors' own original work, which has not been previously published (partially or in full) elsewhere.

3. The research paper reflects the authors' own research work and the analysis result is truthful, complete and we certainly assured that no fabrication of data and images.

4. The research paper properly credits the meaningful contributions of co-authors and co-researchers.

5. All sources used in this research paper are properly cited and those who supported this research financially, by provision of data properly and training were properly acknowledged.

6. We, authors have been personally and actively involved in substantial work leading to the paper, and will take public responsibility for its content.

I agree with the above statements and declare that this submission follows the policies of Springer Guide for Authors and Ethical Statement for publication.

Date:9/18/2021

Corresponding author's signature:

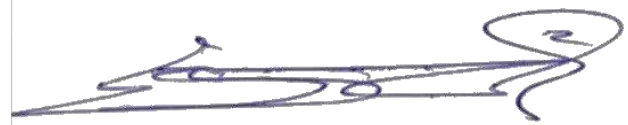

\section{Reference}

A.N. Pettitt, 1979. A Non-parametric to the Approach Problem. Appl. Stat. 28, 126-135.

Alexandersson, H., 1986. A homogeneity test applied to precipitation data. J. Climatol. 6, 661-675. https://doi.org/10.1002/joc.3370060607

Alhamshry, A., Fenta, A.A., Yasuda, H., Kimura, R., Shimizu, K., 2020. Seasonal Rainfall Variability in Ethiopia and Its Long-Term Link to Global Sea Surface Temperatures. J. Water 12, 1-19.

Barrios, A., Trincado, G., Garreaud, R., 2018. Alternative approaches for estimating missing climate data : application to monthly precipitation records in South- Central Chile. For. Ecosyst. 5.

Bichet, A., Diedhiou, A., Hingray, B., Evin, G., Touré, N.D.E., Nana, K., Browne, A., Kouadio, K., 2020. Assessing uncertainties in the regional projections of precipitation in CORDEX-AFRICA. Clim. Chang. 162, 583-601.

Buishand, T.A., 1982. Some Methods for Testing The Homogeneity of Rainfall Records. J. Hydrol. 58, 11-27.

Caloiero, T., Filice, E., Coscarelli, R., Pellicone, G., 2020. A homogeneous dataset for rainfall trend analysis in the Calabria Region (Southern Italy). Water (Switzerland) 12, 13. https://doi.org/10.3390/w12092541

Dile, Y.T., Srinivasan, R., 2013. Evaluation Of Cfsr Climate Data For Hydrologic Prediction In Data- Scarce Watersheds: An Application in the Blue Nile River Basin. Journal. J. Am. Water Resour. Assoc. 1-16. https://doi.org/10.1111/jawr.12182

Eisched, J.K., C.Bruce, Karl, T.R., Diaz, H.F., 1995. The quality control of long-term climatological data using objective data anlysis. J. Appl. Meteorol. Climatol. 34, 2787-2795.

Ekeu-wei, I.T., Blackburn, G.A., Pedruco, P., 2018. Infilling Missing Data in Hydrology : Solutions Using Satellite Radar Altimetry and Multiple Imputation for. Water 10, 1-22. https://doi.org/10.3390/w10101483

El Kasri, J., Lahmili, A., Latifa, O., Bahi, L., Soussi, H., 2018. Comparison of the relevance and the performance of filling in gaps methods in climate datasets. Int. J. Civ. Eng. Technol. 9, 992-10000. https://doi.org/10.1007/9783-030-11881-5_2

Ferrari, G.T., Ozak, E.V., 2014. Missing data imputation of climate datasets: implications to modeling extreme drought events. Rev. Bras. Meteorol. 29, 21-28. https://doi.org/10.1590/s0102-77862014000100003

Fuka, D.R., Walter, M.T., Macalister, C., Degaetano, A.T., Steenhuis, T.S., Easton, Z.M., 2013. Using the Climate Forecast System Reanalysis as weather input data for watershed models. Hydrol. Process. https://doi.org/10.1002/hyp.10073 
Funk, C., Peterson, P., Landsfeld, M., Pedreros, D., Verdin, J., Shukla, S., Husak, G., Rowland, J., Harrison, L., Hoell, A., Michaelsen, J., 2015. The climate hazards infrared precipitation with stations - a new environmental record for monitoring extremes. https://doi.org/10.1038/sdata.2015.66

Gao, Y., Merz, C., Lischeid, G., Schneider, M., 2018. A review on missing hydrological data processing. Environ. Earth Sci. 77, 1-12. https://doi.org/10.1007/s12665-018-7228-6

Golkhatmi, N.S., Sanaeinejad, S.H., Ghahraman, B., Pazhand, H.R., 2012. Extended Modified Inverse Distance Method for Interpolation Rainfall. Int. J. Eng. Invent. 1, 57-65.

Hartkamp, A.D., Beurs, K. De, Stein, A., White, J.W., 1999. Interpolation Techniques for for Climate Variables. NRG-GIS Ser. 99-01. Mex. D.F. CIMMYT 1-35.

Houari, R., Bounceu, A., Tari, A.-K., Kechadi, M.-T., 2014. Handling Missing Data Problems with Sampling Methods, in: 2014 International Conference on Advanced Networking Distributed Systems and Applications (INDS). pp. 2-7. https://doi.org/10.1109/INDS.2014.25

Ibrahim, J.G., Chen, M., Lipsitz, S.R., Herring, A.H., 2005. Missing-Data Methods for Generalized Linear Model: A Comparative Review. J. Am. Stat. Assoc. 100, 332-346. https://doi.org/10.1198/016214504000001844

Ismail, W.N.W., Ibrahim, W.Z.W.Z.W., 2017. Estimation of rainfall and stream flow missing data for Terengganu , Malaysia by using interpolation technique methods. Malaysian J. Fundam. Appl. Sci. 13, 213-217.

K.Srinivasa Raju, D. Nagesh, K., 2014. Multicriterion Analysis in Engineering and Management.

Kashani, M.H., Dinpashoh, Y., 2012. Evaluation of efficiency of different estimation methods for missing climatological data. Stoch Env. Res Risk Assess 26, 59-71. https://doi.org/10.1007/s00477-011-0536-y

Kocsis, T., Kovács-Székely, I., Anda, A., 2020. Homogeneity tests and non-parametric analyses of tendencies in precipitation time series in Keszthely, Western Hungary. Theor. Appl. Climatol. 139, 849-859. https://doi.org/10.1007/s00704-019-03014-4

M. Majmder, 2015. Multi Criteria Decision Making, in: Impact of Urbanization on Water Shortage in Face of Climatic Aberrations,. pp. 35-48. https://doi.org/10.1007/978-981-4560-73-3

Mardani, A., Jusoh, A., MD Nor, K., Khalifah, Z., Zakwan, N., Valipour, A., 2015. Multiple criteria decision-making techniques and their applications - a review of the literature from 2000 to 2014. Econ. Res. 28, 516-571. https://doi.org/10.1080/1331677X.2015.1075139

Moriasi, D.N., Arnold, J.G., Liew, M.W. Van, Bingner, R.L., Harmel, R.D., Veith, T.L., 2007. Model Evaluation Guidline for Systematic Quantification of Accuracy in Wateshed Simulations. Am. Soc. Agric. Biol. Eng. 50, 885-900.

Nash, J.E., Sutcliffe, J. V, 1970. River Flow Forcasting Throgh Conceptual Models Part I A discussion of Principles. J. Hydrol. 10, 282-290.

Patakamuri, S.K., Muthiah, K., Sridhar, V., 2020. Long-Term homogeneity, trend, and change-point analysis of rainfall in the arid district of ananthapuramu, Andhra Pradesh State, India. Water (Switzerland) 12. https://doi.org/10.3390/w12010211

Peugh, J.L., Enders, C.K., 2004. Missing data in educational research: A review of reporting practices and suggestions for improvement. Rev. Educ. Res. https://doi.org/10.3102/00346543074004525

Piazza, A. Di, 2011. The problem of missing data in hydroclimatic time series. Applicationof spatial interpolation techniques to construct a comprehensive of hydroclimatic data in Sicily, Italy.

Pigott, T.D., 2001. Educational Research and Evaluation : An International Journal on Theory and Practice A Review of Methods for Missing Data. An Int. J. Theory Pract. 7, 353-383. https://doi.org/10.1076/edre.7.4.353.8937

Plouffe, C.C.F., Robertson, C., Chandrapala, L., 2015. Environmental Modelling \& Software Comparing interpolation techniques for monthly rainfall mapping using multiple evaluation criteria and auxiliary data sources : A case study of Sri Lanka. Environ. Model. Softw. 67, 57-71. https://doi.org/10.1016/j.envsoft.2015.01.011

Pomerol, J.-C., Barba-Romero, S., 2000. Multicriterion Decision in Management Principles and Practice.

Radi, N.F.A., Zakaria, R., Azman, M.A.Z., 2015. Estimation of missing rainfall data using spatial interpolation and imputation methods, in: AIP Conference Proceedings 1643. pp. 42-48. https://doi.org/10.1063/1.4907423

Raju, K.S., Kumar, D.N., 2018. Impact of Climate Change on Water Resources in India, Journal of Environmental Engineering (United States). https://doi.org/10.1061/(ASCE)EE.1943-7870.0001394

Raju, K.S., Sonali, P., Kumar, D.N., 2016. Ranking of CMIP5-based global climate models for India using compromise programming. Theor Appl Cimatol. https://doi.org/10.1007/s00704-015-1721-6

Romero, R., Guijarro, J.A., Ramis, C., Alonso, S., 1998. A 30-year (1964-1993) daily rainfall data base for the Spanish Mediterranean regions: first exploratory study. Int. J. Climatol. 18, 541-560. https://doi.org/10.1002/(SICI)1097-0088(199804)18:5<541::AID-JOC270>3.0.CO;2-N

Rubin, D.B., 1976. Inference and Missing data. J. Biometrika 63, 581-592.

Sabaei, D., Erkoyuncu, J., Roy, R., 2015. A review of multi-criteria decision making methods for enhanced 
maintenance delivery. ELSEVIER 37, 30-35. https://doi.org/10.1016/j.procir.2015.08.086

Sattari, M.-T., Rezazadeh-Joudi, A., Kusiak, A., 2017. Assessment of different methods for estimation of missing data in precipitation studies Mohammad-Taghi Sattari, Ali Rezazadeh-Joudi and Andrew Kusiak. J. Hydrol. Res. 48, 1032-1044. https://doi.org/10.2166/nh.2016.364

Sattari, M.-T., Rezazadeh-Joudi, A., Kusiak, A., 2016. Assessment of different methods for estimation of missing data in precipitation studies. Hydrol. Res. 48, 1-13. https://doi.org/10.2166/nh.2016.364

Schmitt, P., Mandel, J., Guedj, M., 2015. A Comparison of Six Methods for Missing Data Imputation. J. Biom. Biostat. 6, 1-6. https://doi.org/10.472/2155-6180.1000224

Schneider, T., 2001. Analysis of incomplete climate data: Estimation of Mean Values and covariance matrices and imputation of Missing values. J. Clim. 14, 853-871. https://doi.org/10.1175/15200442(2001)014<0853:AOICDE>2.0.CO;2

Schönwiese, C.-D., Rapp, J., 1997. Clima Te Trend Atlas of Europe Based on Observations 1891-1990.

Teegavarapu, R.S. V, 2009. Estimation of missing precipitation records integrating surface interpolation techniques and spatio-temporal association rules. J. Hydroinformatics 11, 133-146. https://doi.org/10.2166/hydro.2009.009

Teegavarapu, R.S. V, Chandramouli, V., 2005. Improved weighting methods, deterministic and stochastic data-driven models for estimation of missing precipitation records. J. Hydrol. 312, $191-206$. https://doi.org/10.1016/j.jhydrol.2005.02.015

Teegavarapu, R.S. V, Salas, J.D., Stedinger, J.R., 2019. Statistical Analysis of Hydrologic Variables. Methods and Applications. https://doi.org/https://doi.org/10.1061/9780784415177.

Tsegaye, Meshesha; Atsushi, Tsunkekawa; Mitsuru, Tsubo; and Nigussie, H., Meshesha, D.T., Tsunekawa, A., Tsubo, M., Haregeweyn, N., 2012. Dynamics and hotspots of soil erosion and management scenarios of the Central Rift Valley of Ethiopia. Int. J. Sediment Res. 27, 84-99. https://doi.org/10.1016/S1001-6279(12)60018-3

Vieux, B.E., 2004. Distributed Hydrologic Modelling Using GIS 2nd edition.

von Neumann, J., 1941. Distribution of the Ratio of the Mean Square Successive Difference to the Variance. Ann. Math. Stat. 12, 367-395. https://doi.org/10.1214/aoms/1177731677

Wijngaard, J.B., Tank, A.M.G.K., K“ONNEN, G.P., 2003. Himogeneity of the 20th cenetury European Daily Temprature and Precipitation Series. Int. J. Climatol. 23, 679-692. https://doi.org/10.1002/joc.906

Xia, Y., Fabian, P., Stohl, A., Winterhalter, M., 1999. Forest climatology : estimation of missing values for Bavaria , Germany. Agric. For. Mteorolgy 96, 131-144.

Zhu, Y., Tian, D., Yan, F., 2020. Effectiveness of Entropy Weight Method in Decision-Making. Math. Probl. Eng. 20, 1-5. https://doi.org/https://doi.org/10.1155/2020/3564835 


\section{Supplementary Files}

This is a list of supplementary files associated with this preprint. Click to download.

- Appendix.docx 